Introduction Treatment with infliximab for patients with Inflammatory Bowel Disease (IBD) in the UK consists of intravenous infusions usually delivered in hospital via a nurse-led service. Several studies have proven the safety of infliximab infusions at home which also eases the capacity for hospital infusions. However, the uptake in clinical practice has been slow in the UK. We aim to evaluate the safety and patient satisfaction of home infliximab infusions in a district general hospital 4 years after its introduction.

Methods This is a retrospective audit of all IBD patients enrolled in a home infliximab infusion programme from July 2014 to July 2018. Data were collected from the electronic database and case notes. Data collected included serious adverse reactions requiring hospital admission and number of times home infusions were put on hold/stopped because of safety concerns. Patients currently on the home infliximab infusion programmed were interviewed by telephone by 2 Gastroenterology specialist trainees. Satisfaction rate (out of 10) were collected for adequate communication, delivery times, customer service, driver assistance/attitude, nurse support service, clinical waste collection and overall satisfaction.

Results A total of 41 patients were included in the analysis (3 excluded due to insufficient follow up data): median age was 42 years, $19(46.3 \%)$ were women, 9 (22\%) had ulcerative colitis and $32(78 \%)$ had crohn's disease. Three hundred and seventy three (373) infliximab infusions were given at home: there were no deaths and no adverse reactions requiring hospital admission. There were $3(0.8 \%)$ instances where home infliximab infusions were put on hold or stopped as shown in table 1. Patients were given a median number of 7 doses of infliximab in hospital before moving to the home infliximab infusion. The median follow up time on home infliximab was 14 months and the median number of doses given at home was 7 .

Abstract PTU-103 Table 1: Patients who had their home infliximab on hold, rationale for pausing and follow up

\begin{tabular}{|c|c|c|c|c|}
\hline Patient & $\begin{array}{l}\text { Number } \\
\text { of } \\
\text { infusions } \\
\text { in hospital }\end{array}$ & $\begin{array}{l}\text { Number of } \\
\text { infusions at } \\
\text { home prior to } \\
\text { holding }\end{array}$ & $\begin{array}{l}\text { Reason home } \\
\text { infliximab on } \\
\text { hold }\end{array}$ & Follow up \\
\hline 1 & 8 & 14 & $\begin{array}{l}\text { Skin rash - } \\
\text { managed in the } \\
\text { community }\end{array}$ & $\begin{array}{l}\text { A further dose was given in } \\
\text { hospital. Infliximab completely } \\
\text { stopped following similar skin } \\
\text { rash }\end{array}$ \\
\hline 2 & 21 & 32 & $\begin{array}{l}\text { Low blood } \\
\text { pressure } \\
\text { following } \\
\text { infliximab } \\
\text { infusion }\end{array}$ & $\begin{array}{l}\text { Next infliximab dose given in } \\
\text { hospital as precaution }\end{array}$ \\
\hline 3 & 12 & 19 & $\begin{array}{l}\text { Patient became } \\
\text { pregnant }\end{array}$ & $\begin{array}{l}\text { Home infliximab restarted after } \\
\text { pregnancy }\end{array}$ \\
\hline
\end{tabular}

Eighteen (69.2\%) out of 26 patients on home infliximab in July 2018 responded to a telephone interview. Mean and median satisfaction rates were 9.7 and 10 (out of 10).

Conclusion A home infliximab infusion programme for patients with IBD is safe with all adverse reactions being minor and managed in the community. Patient satisfaction rate is high.

\section{PTU-104 NO SURVEILLANCE OR 5-YEAR COLONOSCOPY? THE COST SAVINGS OF DISCONTINUING SURVEILLANCE FOR LOW RISK ADENOMAS}

Benjamin Shandro*, Vincent Chang, Jai Mathur, Parker O'Neill, Christopher Groves, Gareth Sadler, Andrew Poullis. St George's University Hospitals NHS Foundation Trust, London, UK

\subsection{6/gutjnl-2019-BSGAbstracts.463}

Introduction The benefit of colonoscopy surveillance for low risk adenomas (LRAs) is unclear. The BSG currently recommends either no surveillance or 5-year colonoscopy. It has recently been shown that following removal of LRAs, patients are not at increased risk of colorectal cancer compared to the general population. This suggests colonoscopy surveillance in these patients may not be necessary. In particular, patients aged 6-4 years when surveillance is due are eligible for biennial stool testing in the national bowel cancer screening programme (BCSP), which provides a potential alternative for follow up. We aimed to estimate the cost savings and endoscopy capacity that could be generated by discontinuing colonoscopy surveillance for LRAs.

Methods We conducted a retrospective endoscopy database analysis of patients for whom 5-year colonoscopy surveillance had been requested for LRAs between 2013 and 2018 at a London teaching hospital. Patients with inflammatory bowel disease, previous colorectal cancer or Lynch syndrome were excluded. The age at which colonoscopy surveillance was due was calculated. We calculated the annual cost savings and endoscopy capacity that could be generated for our trust by ceasing colonoscopy surveillance for LRAs in patients aged 64 years and in all patients, using the 2018 NHS tariff for diagnostic colonoscopy of $£ 406$.

Results 1035 patients were booked for colonoscopy surveillance for LRAs during the 5-year study period. 51.7\% were male. The mean age at which colonoscopy surveillance was due was 63.5 years (SD 12.6). Discontinuing colonoscopy surveillance in patients aged 6-4 years with LRAs would save our trust $£ 34,997$ per year and generate an additional 87 colonoscopy appointments per year. Discontinuing colonoscopy surveillance in all patients with LRAs would save our trust $£ 84,042$ per year and generate an additional 207 colonoscopy appointments per year.

Abstract PTU-104 Table 1 Annual cost savings and capacity generated by ceasing colonoscopy surveillance in patients with LRAs

\begin{tabular}{|c|c|c|c|c|}
\hline Model & $\begin{array}{l}\text { Patients offered } \\
\text { colonoscopy } \\
\text { surveillance over } 5 \\
\text { years (n (\%)) }\end{array}$ & $\begin{array}{l}\text { Cost of } \\
\text { colonoscopy } \\
\text { surveillance } \\
\text { over } 5 \text { years }\end{array}$ & $\begin{array}{l}\text { Cost } \\
\text { saving } \\
\text { per } \\
\text { year }\end{array}$ & $\begin{array}{l}\text { Colonoscopy } \\
\text { capacity } \\
\text { generated pe } \\
\text { year (n) }\end{array}$ \\
\hline $\begin{array}{l}\text { Colonoscopy } \\
\text { surveillance for } \\
\text { LRAs }\end{array}$ & $1035(100)$ & $\mathrm{f} 420,210$ & f0 & 0 \\
\hline $\begin{array}{l}\text { No colonoscopy } \\
\text { surveillance for } \\
\text { LRAs if aged 6-4 } \\
\text { years }\end{array}$ & $604(58)$ & $£ 245,224$ & $£ 34,997$ & 87 \\
\hline $\begin{array}{l}\text { No colonoscopy } \\
\text { surveillance for } \\
\text { LRAs }\end{array}$ & $0(0)$ & f0 & $\mathrm{f} 84,042$ & 207 \\
\hline
\end{tabular}


Conclusions Significant cost savings can be made, and endoscopy capacity generated, by discontinuing colonoscopy surveillance for LRAs. In the increasingly financially constrained NHS environment this approach should be explored, particularly in patients who are eligible for participation in the BCSP.

\section{PTU-105 AUTOMATED, ALGORITHM BASED EXTRACTION OF BARRETT'S SURVEILLANCE METRICS FROM NATURAL LANGUAGE TEXT IS RELIABLE}

\begin{abstract}
${ }^{1}$ Sebastian Zeki*, ${ }^{2}$ Richard Hackett, ${ }^{1}$ Jason Dunn, ${ }^{1}$ Aaron Bancil, ${ }^{3}$ Sean Preston, ${ }^{3} J o a n n e$ Chin-Aleong, ${ }^{4}$ Jonathan Brown, ${ }^{2}$ Stuart McDonald. 'Guy's and St Thomas' NHH Trust, London, UK; ${ }^{2}$ Tumour Biology, Bart's Cancer Institute, London EC1M, UK; ${ }^{3}$ Barts and the London School of Medicine and Dentistry, Queen Mary University of London, London, UK; ${ }^{4}$ Gloucestershire Royal Hospital, Gloucester, UK
\end{abstract}

\subsection{6/gutjnl-2019-BSGAbstracts.464}

Introduction Patients with Barrett's oesophagus (BE) undergo regular endoscopic surveillance with a view to earlier oesophageal adenocarcinoma detection. Quality monitoring of this programme relies on manual extraction of elements from pathology and endoscopic semi-structured free text reports. Manual extraction is laborious and a significant hindrance to robust, large scale and reproducible quality monitoring.

EndoMineR, a package written in R, (a free, open source computational language) has been developed specifically to automate the extraction of data from endoscopic and associated pathology reports ${ }^{1}$. It contains functions to clean, format and extract elements from free text and perform quality metrics for a range of conditions including in BE.

Aim We assessed the accuracy of the BE extraction algorithms for both endoscopic and pathological elements for $\mathrm{BE}$ on pathology data only as it is the 'worst case scenario' input data, using the EndoMineR package. The functions being assessed were: 1. The extraction of a Prague score, 2. The extraction of the worst pathology grade, 3. The site of biopsied tissue, 4. The site and type of any therapy in the upper GI tract.

Methods Ethics was approved (IRAS number). 60 patient episodes between 14 January 2016 and 30 March 2016 with full text pathology data only were acquired from 8 departments in central London as a training set. Validation was performed on a further 100 pathology reports. The therapy algorithm was performed on a further 100 reports.

Abstract PTU-105 Table 1 Sensitivity, specificity, positive and negative predictive values of each of the functions being assessed

\begin{tabular}{lllll} 
Abstract PTU-105 & Table 1 & & & \\
\hline & Sensitivities & Specificities & PPV & NPV \\
\hline MStage & 97.67 & 78.57 & 0.97 & 0.85 \\
CStage & 94.23 & 97.92 & 0.98 & 0.94 \\
Worst & 97.83 & 62.5 & 0.97 & 0.71 \\
Pathology & & & & \\
PathologySite & 88 & 100 & 1 & 0.89 \\
TherapySite & 95.92 & 82.35 & 0.84 & 0.95 \\
\hline
\end{tabular}

Results Reports were written by 11 different pathologists. The readability index of all the text, using the Fleisch-Kincaid readability index was 11.7 (sd:1.22) indicating an average grammatical complexity. Sensitivity was excellent for all algorithms especially given the difficult input text (Table 1). A reduction in specificity in the detection of worst pathology occurred because of dual reporting of colonoscopy and gastroscopy tissue which also affected the sensitivity of the Pathology Site detection. A variability in how intestinalisation was reported also affected the specificity.

Conclusion

- Reproducible extraction can be done from semi-structured text.

- Further improvements using parts of speech tagging and term mapping will improve the results.

- Such data extraction will allow for upstream automation of quality monitoring, governance and novel metrics.

\section{REFERENCES}

1. Zeki S of Open Source, (2018). EndoMineR for the extraction of endoscopic and associated pathology data from medical reports. Journal Software;3(24):701.

\section{PTU-106 BARRETT'S OESOPHAGUS - ARE WE FOLLOWING THE GUIDELINES?}

${ }^{1}$ Mina Soliman, ${ }^{2}$ Elmuhtady Said, ${ }^{2}$ Kapil Kapur. 'ST George University of London, London, UK; ${ }^{2}$ Barnsley Foundation Trust Hospital, Barnsley, UK

\subsection{6/gutjnl-2019-BSGAbstracts.465}

Introduction Barrett's oesophagus (BO) affects $1-5 \%$ of reflux patients and has a premalignant potential. Several guidelines $1,2,3$ to optimise surveillance are tailored towards discovering dysplasia and hence allow treatment and prevention of cancer. Aim and Methods We aim to evaluate compliance of BO surveillance with the current published guidelines in our centre between June 1st 2017 to May 31st 2018.

Retrospective database search was done using the built-in audit tool of Infoflex v.5 reporting system. Surveillance details were added to an excel spreadsheet against criteria extracted from both the British Society of Gastroenterology and the European Society guidelines. Histology and advice on proposed future surveillance were also reviewed.

Results 164 BO reports were found during the study period. $78 / 164$ (48\%) patients were undergoing surveillance and 86/ 164 (52\%) were newly diagnosed.

In the surveillance group: 54/78 (69\%) were males, mean age 67(4-0) and 24/78 (31\%) females, mean age 60 (range 56 ). Prague classification (PC) was correctly used in $70 / 78$ (89\%). Seattle protocol for biopsy was followed in 55/78 (70\%). Chromoendoscopy was used in 26/78 (33\%). Inspection time was recorded only in $2 / 78$ (2.5\%). In two cases(2/ 78 ), visible lesions were found and described according to the clock face and its distance from incisors. Intestinal metaplasia was confirmed on histology in 72/78 (92\%). Recommended surveillance frequency was consistent with the guidelines in $64 / 72(88 \%)$ of BO without dysplasia but in all 3 cases with dysplasia. In the group presenting to symptomatic service where a new diagnosis of BO was found: 59/86 (68\%) had PC correctly listed. Of the remaining 27/86, all but one were on a surgical list. Additionally, only 41/86 (47\%) of the suspected new BO were biopsied. Reasons for not taking biopsies were listed in 10 cases only.

Conclusions There is significant variability in the execution and surveillance of BO. The correct use of Seattle protocol, chromoendoscopy and recording the time spent inspecting the $\mathrm{BO}$ are all important service improvements that could be 